\title{
Application of a Fixed Water Mist System in a Power Transformer Room
}

\author{
YONGSHIK HAN, BYUNGIL CHOI, and MYUNGBAE KIM \\ Environment and Energy Research Division \\ Korea Institute of Machinery \& Materials \\ 171 Jang-Dong \\ Yusong, Daejeon, 305-343, Korea
}

\begin{abstract}
This study deals with the fire suppression capability and cooling characteristics required to prevent spontaneous re-ignition in a power transformer room. A water mist system was considered as a possible alternative to a gaseous suppression system. High- and lowpressure water mist systems were examined. The power transformer examined in this study occupied about $7 \%$ of a $10 \mathrm{~m} \times 10 \mathrm{~m} \times 10 \mathrm{~m}$ test room. Full-scale suppression tests were performed for six different fire scenarios: two spray fires, three pool fires, and one cascade fire. Three reduced-scale models were used to estimate the cooling characteristics required for the power transformer and to calculate the necessary discharge time for the water mist to prevent spontaneous re-ignition. The fire suppression test results demonstrated that the high-pressure system was superior to the low-pressure system, especially considering oxygen depletion and the ambient temperature distribution. In the cooling tests, the discharge time required to prevent spontaneous reignition was estimated to be about $12 \mathrm{~h}$ for both the high- and low-pressure systems.
\end{abstract}

KEYWORDS: water mist, fire suppression, re-ignition, transformer room INTRODUCTION

Water mist systems have been viewed as possible alternatives to gaseous suppression systems for use in electrical equipment rooms. Even though the potential applications include telecommunication facilities and control, computer, and power transformer rooms, the development of water mist facilities in these areas has been limited. Although gaseous suppression systems are good for suppressing fires, they do not prevent the reignition that occurs when the fire source has a large latent heat capacity.

A typical power transformer in Korea converts $154 \mathrm{kV}$ to $22.9 \mathrm{kV}$ with a power capacity of up to $60 \mathrm{MVA}$. The power transformer has a core that weighs more than $60,000 \mathrm{~kg}$, which is filled with dielectric oil to cool the transformer core. If an accident such as a short circuit occurs, the core temperature can increase to up to $700^{\circ} \mathrm{C}$ [1]. Therefore, the core and dielectric oil have a large latent heat capacity and can become a source of reignition after the initial fire has been extinguished. In reality, several fire accidents in Korean power transformers have revealed that spontaneous re-ignition does occur after the initial fire has been extinguished. Existing gaseous extinguishing systems cannot provide a solution to the re-ignition problem caused by the large latent heat capacity of the transformer core.

The object of this study was to evaluate the capabilities of a water mist system for suppressing a fire and preventing re-ignition in a power transformer room. High- and low-pressure water mist systems were considered. In the fire suppression tests, full-scale experiments with six different fire scenarios were performed. The time required to extinguish the fire and the spatial distributions of the temperature and oxygen were 
measured to evaluate the suppression capability of the system. However, it was impossible to estimate the required discharge time for the water mist to prevent spontaneous re-ignition using full-scale cooling tests because the core weighed about $60,000 \mathrm{~kg}$. Therefore, three reduced-scale models were examined and the discharge times for the corresponding full-scale tests were estimated from these results using a similarity law.

The fire suppression test results showed that the high-pressure system was superior to the low-pressure system, especially considering oxygen depletion and the ambient temperature distribution. In the cooling tests, the discharge time required to prevent spontaneous re-ignition was estimated to be about $10 \mathrm{~h}$ for both the high- and lowpressure systems.

\section{ANALYSIS OF POWER TRANSFORMER FIRE INCIDENTS}

The dimensions of a typical Korean power transformer room are $10 \mathrm{~m} \times 10 \mathrm{~m} \times 10 \mathrm{~m}$. The power transformer (width: $6.0 \mathrm{~m}$, depth: $2.0 \mathrm{~m}$, and height: $3.0 \mathrm{~m}$ ) and oil reservoir tank are located in the central part of the room. An incident investigation [1] reported that the temperature of a transformer core increased to about $700^{\circ} \mathrm{C}$ owing to a short circuit inside the transformer, which led to heat transfer from the core to the dielectric oil. Once the oil started to vaporize, internal pressure built up. When the pressure exceeded a certain limit, the tank ruptured at a weak point. It can therefore be assumed that the fire occurred from heated oil leaking through ruptured parts of the external plate, piping, or fittings of the transformer. As the heat capacity of the core was very high, the core acted continuously as an ignition source during the fire incident. Hence re-ignition occurred, even though the initial fire was suppressed. The damaged portion of the transformer and the fire incident are illustrated in Figs. 1 and 2.

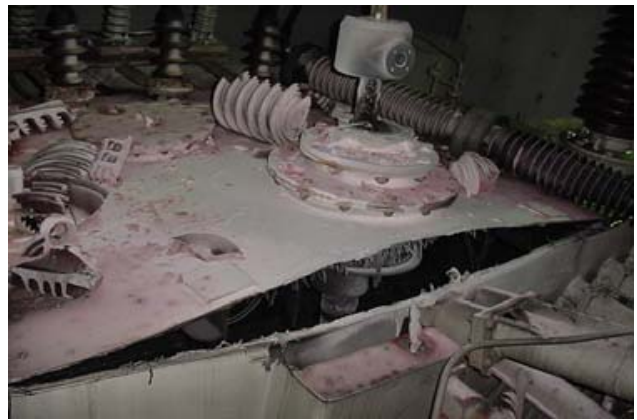

Fig. 1. Damaged portion of the transformer.

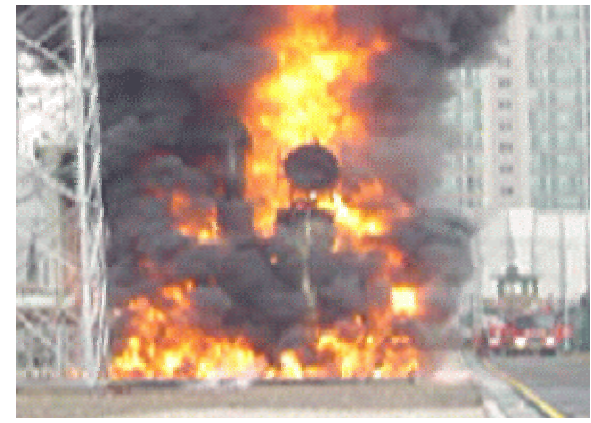

Fig. 2. Transformer fire incident.

\section{FIRE SUPRESSION TESTS}

\section{Full-scale Fire Scenarios}

From a review of the fire procedure [1], the structure of the room, and other references that suggest fire scenarios for an engine room [2], three types of fire were deemed important. These included two spray fires, three pool fires, and one cascade fire. The six fire scenarios are summarized in Table 1 and Fig. 3. The L-10M fire consisted of four 2.5-MW fires, each partially hidden by the transformer mockup, and the L-01M fire was totally hidden by the transformer mockup. 
Table 1. Fire scenarios for the transformer room.

\begin{tabular}{|c|c|l|l|}
\hline Symbol & Fire type & \multicolumn{1}{|c|}{ Fire origin } & \multicolumn{1}{|c|}{ Remarks } \\
\hline S-01M & $\begin{array}{c}\text { Spray fire } \\
\text { (1 MW) }\end{array}$ & $\begin{array}{l}1 \mathrm{~m} \text { above the top surface } \\
\text { of the transformer }\end{array}$ & $\begin{array}{l}\text { Full-cone }\left(120^{\circ}\right) \text {, diesel } \\
\text { oil } 0.03 \mathrm{~kg} / \mathrm{s}, 8.5 \mathrm{bar}\end{array}$ \\
\hline S-06M & $\begin{array}{c}\text { Spray fire } \\
\text { (6 MW) }\end{array}$ & $\begin{array}{l}1 \mathrm{~m} \text { above the top surface } \\
\text { of the transformer }\end{array}$ & $\begin{array}{l}\text { Full-cone }\left(80^{\circ}\right) \text {, diesel } \\
\text { oil } 0.16 \mathrm{~kg} / \mathrm{s}, 8.0 \mathrm{bar}\end{array}$ \\
\hline $\mathrm{U}-06 \mathrm{M}$ & $\begin{array}{l}\text { Pool fire } \\
(10 \mathrm{MW})\end{array}$ & $\begin{array}{l}\text { Floor around the corners of } \\
\text { the transformer }\end{array}$ & $\begin{array}{l}\text { four } 0.6 \mathrm{~m} \times 1.4 \mathrm{~m} \text { fires, } \\
\text { heptane }\end{array}$ \\
\hline L-01M & $\begin{array}{l}\text { Pool fire } \\
(1 \mathrm{MW})\end{array}$ & $\begin{array}{l}\text { Fop surface of the } \\
\text { transformer }\end{array}$ & $\begin{array}{l}\text { two } 0.6 \mathrm{~m} \times 1.4 \mathrm{~m} \text { fires, } \\
\text { heptane }\end{array}$ \\
\hline $\mathrm{C}-12 \mathrm{M}$ & $\begin{array}{c}\text { Cascade fire } \\
(12 \mathrm{MW})\end{array}$ & $\begin{array}{l}\text { Front side of the } \\
\text { transformer }\end{array}$ & Heptane \\
\hline
\end{tabular}

$* 0.6 \mathrm{~m} \times 1.4 \mathrm{~m}$ : size of the oil-drain pit under the transformer

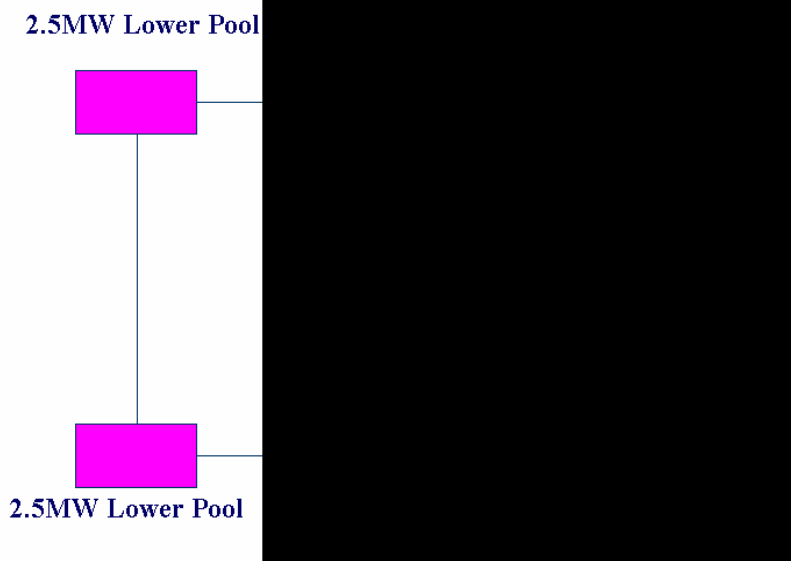

Fig. 3. Top View of the transformer mock-up and suggested fire scenarios. (L-10M consists of four pool fires at the four corners of the mock-up at floor level).

\section{Test Facilities and Methods}

Several series of full-scale fire tests were conducted with high- and low-pressure water mist systems to determine the best nozzle configuration [3]. The hollow cone type highpressure nozzle has a k-factor of 2.4 and it's SMD and Dv0.9 measured at the position of $1 \mathrm{~m}$ apart from the nozzle tip along the center of spray cone are $76.4 \mu \mathrm{m}$ and $123.5 \mu \mathrm{m}$, respectively. The optimum layouts of the nozzle configuration and the specifications of each water mist system are shown in Fig. 4.

Thermocouple trees were used to measure the wall temperature and spatial temperature distribution as functions of height in the transformer room. The temperature of each fire source was also measured to identify when the fire was extinguished, as were the oxygen concentrations at the floor and top surface level of the transformer mockup. All of the fire experiments were visualized using four CCD cameras. 


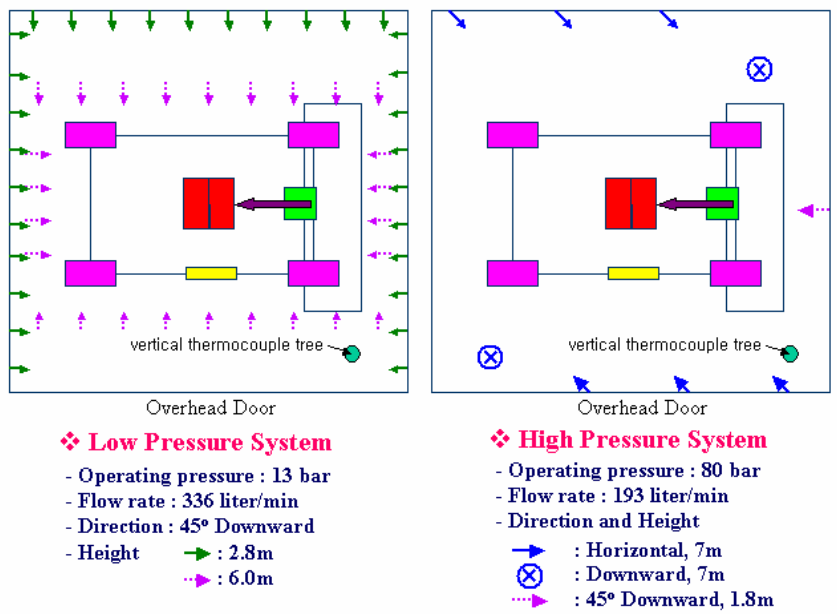

Fig. 4. Nozzle configuration.

The water mist system was operated $15 \mathrm{~s}$ after ignition. The time required to extinguish the fire was recorded by observing the CCD screen and confirmed by analyzing the record of the thermocouple located in each fire source.

\section{Experimental Results and Discussion}

The times required to extinguish the fires using the high- and low-pressure systems are presented in Table 2. These times were measured from ignition. The spray fires $(\mathrm{S}-01 \mathrm{M}$, $\mathrm{S}-06 \mathrm{M})$ were easily extinguished while the hidden fires (L-01M, L-10M) were hard to extinguish. For all cases, the high-pressure system performed better than the low-pressure system.

Figure 5 contains a typical photo of the fire suppression experiment. It shows that both the water mist itself and the smoke flow induced by the water mist injection attacked the fire.

Table 2. Fire extinguishing times (s).

\begin{tabular}{|c|c|c|}
\hline $\begin{array}{c}\text { Fire } \\
\text { scenario }\end{array}$ & $\begin{array}{c}\text { High } \\
\text { pressure }\end{array}$ & $\begin{array}{c}\text { Low } \\
\text { pressure }\end{array}$ \\
\hline S-01M & 40 & 44 \\
S-06M & 70 & 179 \\
L-10M & 429 & 1084 \\
U-06M & 431 & 509 \\
L-01M & 956 & Failed \\
C-12M & 113 & 171 \\
\hline
\end{tabular}




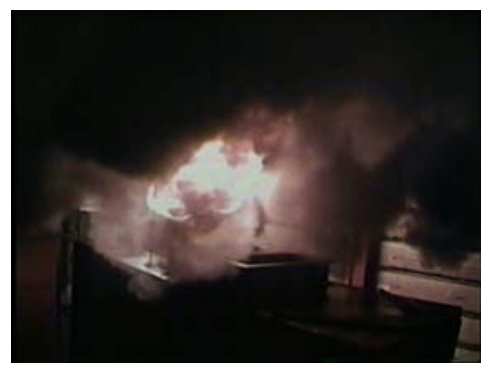

Fig. 5. Typical photo of the fire suppression experiment.

Figure 6 shows the temperature distribution as a function of height and the oxygen concentration at floor level for the $6 \mathrm{MW}$ spray fire $(\mathrm{S}-06 \mathrm{M})$. These measurements clearly elucidate the performance difference between the high- and low-pressure systems. For the low-pressure system, temperature distribution was stratified with height, and the temperature difference between the floor and ceiling was greater than $300^{\circ} \mathrm{C}$. On the other hand, the temperature difference for the high-pressure system was less than $100^{\circ} \mathrm{C}$. This implies that the high-pressure system cooled the surroundings more effectively than did the low-pressure system. The oxygen concentration for the high-pressure system decreased more rapidly as compared to the low-pressure system. The rapid cooling and oxygen depletion that occurred with the high-pressure system resulted in better extinguishing performance.
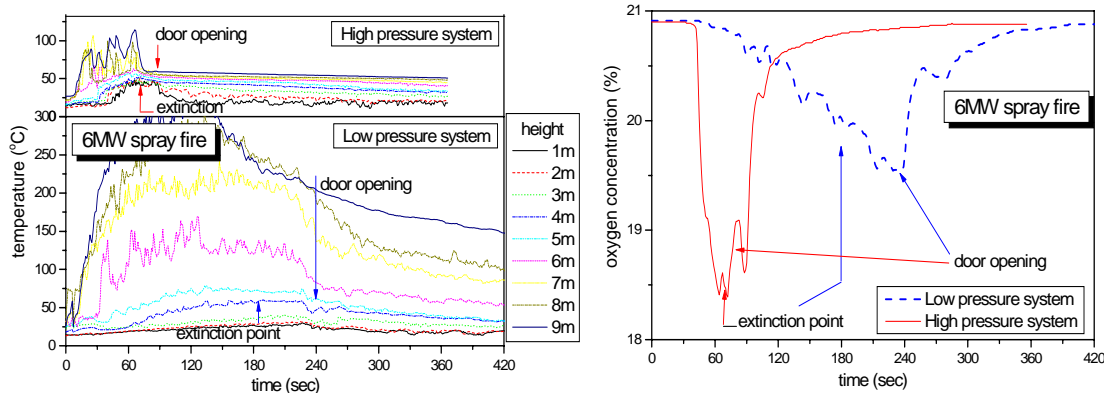

Fig. 6. Temperature distribution and oxygen concentration for S-06M.

The same ambient temperature and oxygen concentration trends were also found in the cascade fire, C-12M. The cooling characteristics of the surroundings and the oxygen depletion for the $\mathrm{C}-12 \mathrm{M}$ fire are depicted in Fig. 7. In particular, the oxygen concentration of the high-pressure system was reduced to $16 \%$. However, it remained at $20 \%$ for the low-pressure system. As the high-pressure system had more momentum than the low-pressure system, it could induce stronger mixing flows. The rapid decrease of the oxygen concentration for the high-pressure system was owing to the migration of smoke from the upper part of the room caused by the strong mixing flow.

In general, water mist extinguishes a fire by directly cooling the fuel surface, by cooling the fire itself, and by depleting $\mathrm{O}_{2}$ owing to the water vapor. From the above experimental results, the oxygen depletion owing to the low $\mathrm{O}_{2}$ smoke flow that is induced by water mist injection could be another fire extinguishing mechanism. 

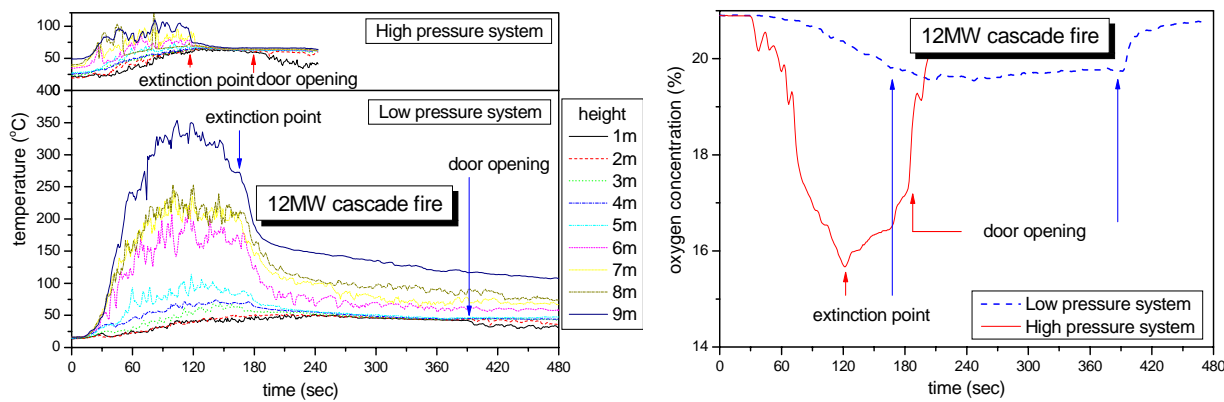

Fig. 7. Temperature distribution and oxygen concentration for C-12M.

\section{COOLING CHARACTERISTICS TO PREVENT RE-IGNITION}

In this section, the cooling performance required for a water mist system to prevent auto re-ignition in an indoor power-transformer is described. As the heat capacity of the transformer core is very large, the core acts continuously as an ignition source during the fire. In these tests, the simulated re-ignition fire was caused by a dielectric oil vapor leak. To estimate the required discharge time of water mist to prevent spontaneous re-ignition, three reduced-scale models were used in the experiments for the sake of convenience, because a transformer core weighs about 60 tons. The discharge times for the full-scale tests were estimated from the results of the reduced-scale models using a similarity law.

\section{Test Facilities}

Water mist nozzles were installed in the transformer core as shown in Fig. 8. Heat transfer occurred from the core to the dielectric oil, which had a boiling point of $370^{\circ} \mathrm{C}$. Table 3 shows the energy budget of the three small-scale models used to predict the required cooling performance, plus an additional 1/18 scale model that was used only to observe several phenomena expected in the larger-scale experiments.

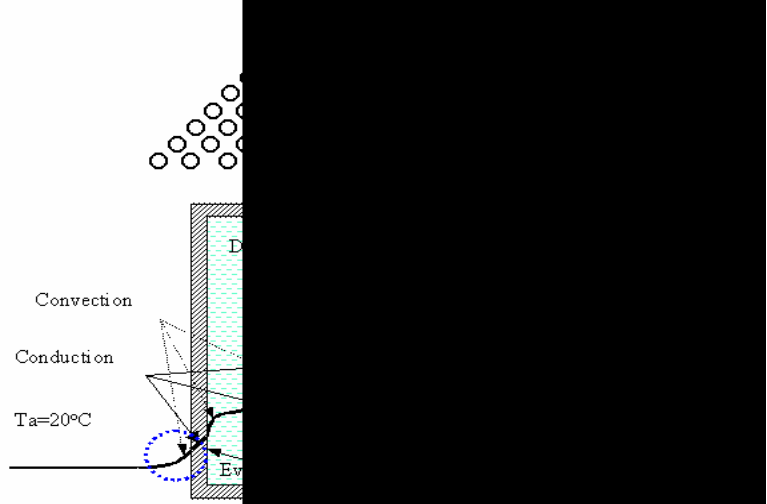

Fig. 8. Cooling characteristics required to prevent re-ignition. 
Table 3. Outline of the small- and full-scale energy budgets (core temperature $=700^{\circ} \mathrm{C}$ ).

\begin{tabular}{|c|c|c|c|c|}
\hline Scale & $\begin{array}{c}\text { Core Weight } \\
(\mathbf{k g})\end{array}$ & $\begin{array}{c}\text { Core Dimensions } \\
(\mathbf{m} \times \mathbf{~ m} \times \mathbf{m})\end{array}$ & $\begin{array}{c}\text { Oil Volume } \\
(\mathbf{l i t e r})\end{array}$ & $\begin{array}{c}\text { Energy of Core } \\
(\mathbf{k J})\end{array}$ \\
\hline $1 / 18$ & 9 & $0.13 \times 0.13 \times 0.13$ & 7.9 & 5,724 \\
\hline $1 / 9$ & 82 & $0.37 \times 0.13 \times 0.21$ & 36 & 26,502 \\
\hline $1 / 5$ & 480 & $0.66 \times 0.24 \times 0.39$ & 214 & 154,560 \\
\hline $1 / 3$ & 2,222 & $1.10 \times 0.40 \times 0.64$ & 989 & 715,484 \\
\hline $1 / 1$ & 60,000 & $3.30 \times 1.20 \times 1.92$ & 26,700 & $* 19,320,000$ \\
\hline
\end{tabular}

* Heat of $10 \mathrm{MW}$ fire for $5.3 \mathrm{~h}$

The same high- and low-pressure water mist systems that were used in the fire suppression experiments were also used here to provide consistency between the two sets of tests. According to the fire scenario for the transformer room, the temperature of the transformer core rose to about $700^{\circ} \mathrm{C}$ owing to a short circuit. This seems to be overestimated because it corresponds to a $10 \mathrm{MW}$ fire burning for $5.3 \mathrm{~h}$. However, this scenario was adopted to ensure a safer measure against fires in power transformers.

\section{Temperature Measurement for the 1/18-scale Model}

To ensure the safety of the large-scale experiments and obtain a description of the overall physics, the temperatures at several locations of the transformer core were measured using the 1/18 scale model. The heated core was placed into an oil bath. Strong boiling of the oil was observed on the core surface because the initial core temperature was much higher than the boiling point $\left(370^{\circ} \mathrm{C}\right)$ of the oil. The core temperatures decreased very rapidly during the initial period, but they decreased much slower after $270 \mathrm{~s}$, as shown in Fig. 9. During the initial period, there was a temperature gradient inside the core owing to the strong boiling heat transfer. During the final period, the inside temperature of the core tended to remain constant with time and boiling heat transfer did not exist because the core cooled down to a temperature that was less than the boiling point of the oil. Heat will be transferred by conduction and convection, but consequently, during the final period, the core was assumed to be a lumped heat capacity system in which solid conduction was negligible. These observations will be applied to the heat transfer analysis for the similarity relationship between the full-scale and reduced-scale models.

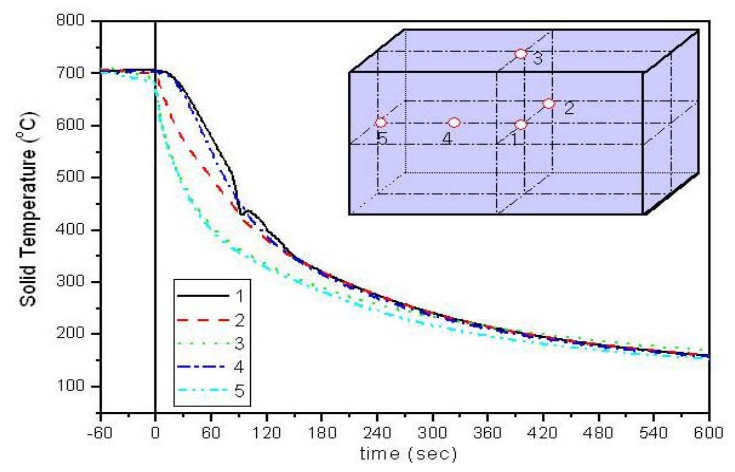

Fig. 9. Temperature change of the transformer core in the $1 / 18$-scale model. 


\section{Simple Similarity Law Between the Full-scale and Reduced-scale Models}

To properly scale water mist protection of power transformer fires, the following two key items should be considered: 1) scaling of heat transfer between the transformer core and the transformer oil in bath; 2) scaling of the interaction between the fire and water mist sprays outside the transformer. The $2^{\text {nd }}$ item, however, is a very complicated phenomenon and needs experimental data for the interaction between the flame and the mist on the scale of the flame thickness. The data for this interaction could not be obtained in this experiment. Since, the most important scaling parameter is thought to be the oil vaporization inside of the transformer, only the heat transfer between the core and the oil for scaling was considered.

According to experimental results obtained using the 1/18 scale model, auto re-ignition is closely related to core temperature, which is governed by the boiling heat transfer during the initial period. During the final period, a uniform temperature is obtained within the core. One-dimensional heat transfer will be assumed to provide a simple analysis (see Fig. 10).

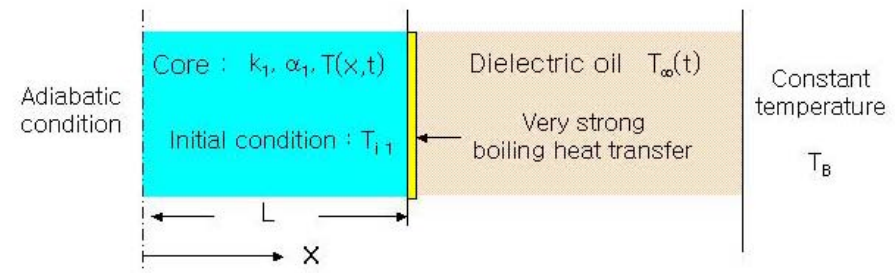

Fig. 10. Heat transfer model in a power transformer.

The core temperature during the initial period is qualitatively dominated by conduction in the core because the boiling heat transfer near the core surface can be treated as a boundary condition. Thus, the governing equation for the core is

$$
\frac{\partial T^{*}}{\partial t^{*}}=\frac{\partial^{2} T^{*}}{\partial x^{* 2}} \quad\left(0 \leq x^{*} \leq 1\right), \quad T^{*}=\frac{T-T_{B}}{T_{i 1}-T_{B}}, \quad x^{*}=\frac{x}{L}, \quad t^{*}=\frac{\alpha_{1} t}{L^{2}} .
$$

where $T$ is the core temperature, $T_{B}$ is the boiling temperature of the oil, and $t$ is time. Here, $\alpha_{1}$ is the thermal diffusivity and $L$ is the length scale of the core. Therefore, the time scales for the initial period can be correlated as follows:

$t=\frac{L^{2}}{\alpha_{1}} t^{*}$, full scale : $t_{f u l l}=\frac{L^{2}}{\alpha_{1}} t^{*}, 1 / N$ reduced scale: $t_{1 / N}=\frac{(L / N)^{2}}{\alpha_{1}} t^{*}$.

During the final period, in which boiling heat transfer does not occur, the heat transfer characteristics can be modeled by the lumped heat capacity system. Conduction in the oil is negligible in comparison with convection. In this case, the governing equation for the core and oil is

$$
\frac{d T^{*}}{d t^{*}}=T^{*} \quad \text { with } T^{*}(0)=1 ., \quad T^{*}=\frac{T-T_{\infty}}{T_{i 1}-T_{\infty}}, \quad x^{*}=\frac{x}{L}, \quad t^{*}=\frac{h t}{\rho C_{p} L} .
$$


where $\rho$ and $C_{p}$ are the density and specific heat of the core, and $h$ is the heat transfer coefficient in the dielectric oil. If we assume that the heat transfer coefficient is constant over different scales, the time scales during the final period are:

$t=\frac{\rho C_{p} L}{h} t^{*}$, full scale: $t_{\text {full }}=\frac{\rho C_{p} L}{h} t^{*}, 1 / N$ reduced scale: $t_{1 / N}=\frac{\rho C_{p} L / N}{h} t^{*}$.

Consequently, we can suppose that the times in full-scale tests can be determined with the following limit scaling law:

$t_{\text {full }}=N^{2} t_{1 / N}$, for the initial period, $t_{\text {full }}=N t_{1 / N}$. for the final period

where $N$ is the ratio of the length scales.

The analytic scaling law has a weak point in boiling period because the boiling is the function of the temperature difference between the core and the oil. For more accurate scaling, the boiling phenomenon itself should be considered. Therefore, the two scale laws in Eq. 5 are the limit cases only and the real scale law shall lie between the two limit cases. In reality, the scaling was obtained by the fitting of experimental results of different scale models. It will be shown in next chapter that the scaling law by the fitting of the temperature of the core lies between two limit cases.

\section{Experimental Results and Discussion}

Cooling experiments using a water mist system were performed at three different scales $(1 / 9,1 / 5$, and 1/3) with the same arrangement and discharge conditions as in fire suppression tests. Details of the transformer mockup and location of thermocouple tree are depicted in Fig. 11, 6 thermocouples including 2 at core center were installed to measure the core temperature. The typical experimental procedure is illustrated in Fig. 12. The heated core was placed into the oil tank, and the tank was closed with a cap. The oil vaporized inside the tank, and oil gas leaked out through a gap between the cap and the wall of the tank. As shown in Fig. 12, spontaneous ignition occurred, and the water mist was discharged to suppress the fire. After the fire had been extinguished, auto re-ignition would occur if the water mist were stopped.

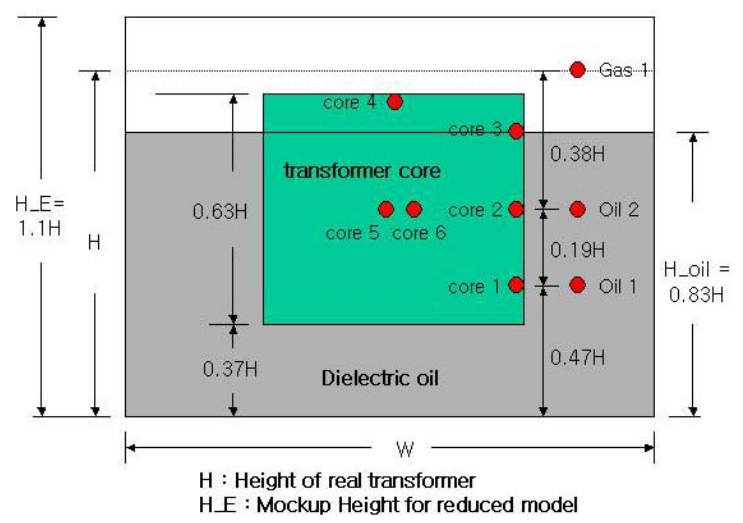

Fig. 11. Reduced mockup and thermocouple tree in core and oil bath. 


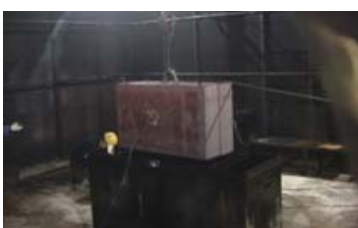

Putting core in

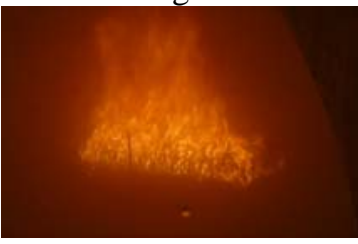

Water mist on

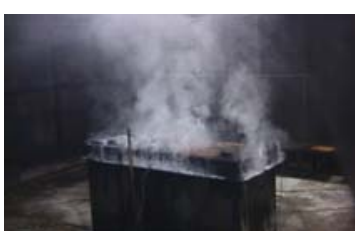

Close the cover of oil tank

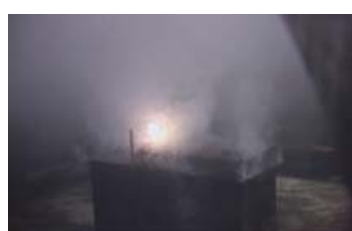

Self ignition

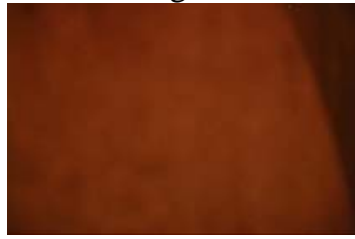

Re-ignition

Fig. 12. Typical photos of the cooling experiments.

Figure 13 shows the experimental results for the reduced-scale models. Data could not be obtained for the $1 / 3$ scale model owing to a thermocouple failure during the experiment. As the core temperature decreased continuously, the repeating cycle (ignition / water injection / extinguish / stop the injection / re-ignition) was eventually not sustained once the system reached a safe open condition for which re-ignition no longer occurred.

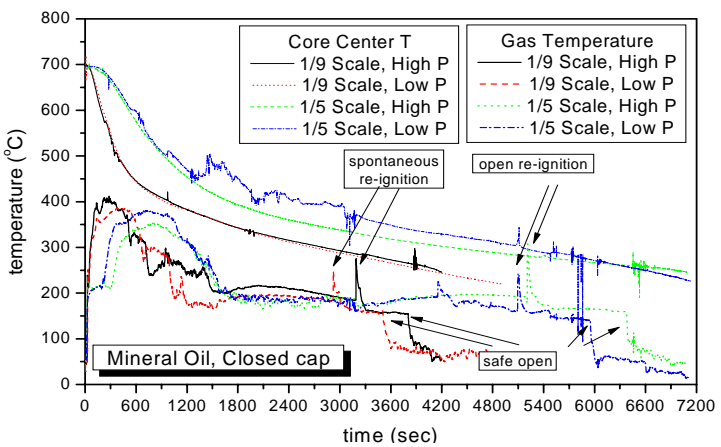

Fig. 13. Cooling simulations for the reduced-scale models.

The full-scale behavior, shown in Fig. 14, was predicted from the reduced-scale results using the following scaling law obtained by the fitting of the core temperature:

$t_{\text {full }}=N^{1.5} t_{1 / N}\left(T_{\text {core }} \geq 500{ }^{\circ} C\right), \quad t_{\text {full }}=N t_{1 / N}\left(T_{\text {core }} \leq 500{ }^{\circ} C\right)$.

This scaling law is different from that of the heat transfer analysis (Eq. 5) in initial period and is same in final period. Figure 13 and 14 show the temperatures of the core and the gas vaporized inside the transformer mockup. The vaporized gas temperature represents the consequent output of heat transfer between the core and the oil. The fact that the gas temperature was properly scaled by the scale law for the core temperature implies that the scaling result is appropriate although somewhat crude. 


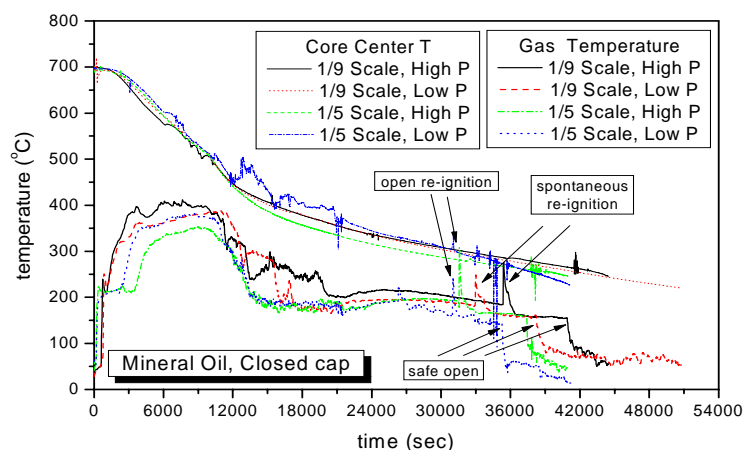

Fig. 14. Prediction of full-scale situation.

The experimental results are presented in Table 4, in which the "safe-open-time" is the time when re-ignition no longer occurred despite an abrupt opening of the transformer cap. The results show that the cooling time required to prevent spontaneous re-ignition is about $12 \mathrm{~h}$, including a sufficient safety margin. It should be noted that there was no significant difference between times required for the high- and low-pressure systems, despite the different discharge rates of $193 \mathrm{l} / \mathrm{min}$ and $320 \mathrm{l} / \mathrm{min}$, respectively.

Table 4. Estimated cooling times required to prevent re-ignition.

\begin{tabular}{|c|c|c|c|c|c|}
\hline \multirow[b]{2}{*}{ Oil Type } & \multirow[b]{2}{*}{ Scale } & \multirow[b]{2}{*}{ System } & \multirow{2}{*}{$\begin{array}{l}\text { Spontaneous } \\
\text { Re-ignition }\end{array}$} & \multicolumn{2}{|c|}{ Safe-open Time (hr) } \\
\hline & & & & Small-scale & $\begin{array}{l}\text { Prediction for } \\
\text { Full-scale }\end{array}$ \\
\hline \multirow{5}{*}{$\begin{array}{l}\text { Mineral } \\
\text { oil }\end{array}$} & \multirow{2}{*}{$1 / 9$} & High pressure & $\bigcirc$ & 1.06 & 11.37 \\
\hline & & Low pressure & $\bigcirc$ & 0.97 & 10.62 \\
\hline & \multirow{2}{*}{$1 / 5$} & High pressure & $\mathrm{O}$ & 1.77 & 10.39 \\
\hline & & Low pressure & $\mathrm{O}$ & 1.65 & 9.80 \\
\hline & $1 / 3$ & High pressure & 0 & N/A & N/A \\
\hline
\end{tabular}

To obtain more accurate results, experiments using many reduced scale models and more realistic re-ignition scenarios are required.

\section{CONCLUSIONS}

To evaluate whether a water mist system is a possible alternative to a gaseous suppression system in a power transformer room, the fire suppression capabilities of a water mist system and the cooling characteristics required to prevent spontaneous reignition were examined. Six different fires were analyzed, and both high- and lowpressure water mist systems were tested.

The full-scale fire suppression tests demonstrated that the high-pressure system performed better than the low-pressure system. The room temperature distribution and oxygen concentration measurements revealed that the high-pressure system provided fine water mist protection, which depleted the oxygen and cooled the surroundings.

The cooling performance of a water mist system for a power transformer was tested using four reduced-scale models. The discharge time required to prevent auto re-ignition was obtained from the similarity relationship between the full-scale tests and the reducedscale models. The results showed that the cooling time required to prevent spontaneous 
re-ignition was about $12 \mathrm{~h}$, including a sufficient safety margin. There was no significant difference between the high- and low-pressure systems.

\section{REFERENCES}

[1] Analysis of Transformer Incidents, Korea Electric Power Corporation, 2003.

[2] IMO MSC/circ.668/728, "Alternative Arrangements for Halon Fire Extinguishing Systems in Machinery Spaces and Pump Rooms," International Maritime Organization, 1996.

[3] "Fire Extinguishment Tests With Water Mist Systems," KIMM Report BSG1541059.M, Korea Institute of Machinery and Materials, 2004. 